Journal of Mathematics and Statistics 8 (1): 136-143, 2012

ISSN 1549-3644

(C) 2012 Science Publications

\title{
On Prediction of Depreciation Time of Fossil Fuel in Malaysia
}

\author{
Nora Muda and Tey Jin Pin \\ School of Mathematical Sciences, Faculty of Science and Technology \\ University Kebangsaan Malaysia, 43600 Bangi, Selangor, Malaysia
}

\begin{abstract}
Problem statement: The fossil fuels play a crucial role in the world energy markets. Demand for fossil fuels become increasingly high and worrisome, because of fossil fuels will be significantly reduced and ultimately exhausted. This study was conducted to predict the depreciation time of fossil fuels in Malaysia and estimate the time remaining before the fossil fuels will finish. Approach: To predict the depreciation time of fossil fuels, the reserves, consumption and prices of fossil fuel will be used. The prediction of fossil fuel reserves were estimated using ratio of fossil fuel reserve versus consumption, Klass Model and Modified Klass Model. The prediction time will give us the opportunity to prepare for the coming energy crisis and discover new energy sources. The results from the analysis will be concluded alongside with the Olduvai Theory and Hubbert Peak Theory. Both of the theories are highly related to the energy crisis. The Olduvai Theory states that the industrial civilization will last for approximately 100 year: circa 1930-2030. As for Hubbert Peak Theory, it can estimate the total amount of fossil fuels available based on the production rate from time to time. Results: Due to the vast usage of petroleum, it will be depleted faster than natural gas and coal. After 14 years, natural gas and coal will replace petroleum as a fossil fuel and coal would then be the major fossil fuels. Based on the results from Hubbert Peak Theory, the rate of production of petroleum has reached the maximum level in 2004 and started to decline since that time; while in the Olduvai theory, it has explained that the life expectancy of the industrial civilization was found to be ended in 2030 . Petroleum will be spent over in 2020, followed by natural gas in 2058 and coal around the year 2066. Conclusion: So far, Malaysia has not facing disconnection of electricity as other developed countries. When this happens, it gives the meaning of the end of the industrial civilization where the electric power grids go down and never come back up. If there is no substance that can replace fossil fuels to continue in the industrial civilization, human civilization will be facing the fate of collapse.
\end{abstract}

Key words: Fossil fuel, depletion time, Klass model, modified Klass model, olduvai theory, Hubbert peak theory

\section{INTRODUCTION}

Fossil fuels are natural resources that were formed by the decomposition of organisms buried for millions of years. Fossil fuel consisting of petroleum, natural gas and coal. Petroleum or crude oil is a complex mixture of hydrocarbons and typically exist in liquid form. There is thick, black petroleum such as tar and there are clear like water. Petroleum is not useful in its raw form, but produces useful products such as petrol, kerosene and lubricating oil refining process. Natural gas is similar to petroleum, but exists as a gas. It is colourless and odourless. Most natural gas is formed by methane, ethane, propane, butane and pentane, which is also the composition of natural gas from the petroleum refining process. Furthermore, coal is similar to the black stone and is divided into three main types, anthracite, bituminous and lignite. Unlike petroleum and natural gas, coal is formed by the decomposition of plants alone. Energy from sunlight is absorbed and stored by plants millions of years ago and released when the plant decays. The nature of fossil fuels that are flammable provides the potential to generate more energy for electricity generation from the steam, internal combustion engines, as well as cooking.

Since the discovery of fossil fuels, human civilization has been switched to the Industrial Age. The energy produced by fossil fuels allows humans to operate large machinery to overcome human limitations. Heavy objects can be lifted and moved easily and buildings can be constructed in a shorter time. All this contributes to global economic growth and bring human civilization to a higher level. Until now, fossil fuels still play an important role in the

Corresponding Author: Nora Muda, School of Mathematical Sciences, Faculty of Science and Technology, University Kebangsaan Malaysia, 43600 Bangi, Selangor, Malaysia Tel: 60389213718 Fax: +60389254519 
world energy markets because energy is an important source of growth in the world. Fossil fuels are natural resources that cannot be renewed and will be exhausted in the near future. Because of technological progress and economic growth, demand for fossil fuels becomes increasingly high. It is a fact that fossil fuels are nonrenewable resources hidden underneath the earth and will be depleted one day. As time progresses, the consumption and demand for fossil fuels are increasing. There is a fear that they will be diminished in the near future.

According to Shafiee and Topal (2009), reserves of fossil fuel related to usage and price. The reserve of petroleum and natural gas has shown a positive relationship with usage but has negative relationship with prices. On the other hand, reserves of coal showed a negative relationship with usage, but positive with price. Shafiee and Topal (2009) has found that the prediction of depreciation time of petroleum, natural gas and coal for the world will be depleted around 34, 36 and 106 years. Duncan (2001) highlights the theory that explains the world energy production and world population is related to the industrial civilization, where the industry expects that the life expectancy is approximately 100 years, i.e. between the years 1930 to 2030. This theory is called the Olduvai Theory that predicts the time of disconnection of electricity (blackout) where the electric power grids go down and never come back up.

Korpela, 2006 has debated on the need for alternative energy sources to address concerns over the decision of fossil fuels. This has been raised by Hubbert (1949) which states that the era of fossil fuels is very short. In the past, people use solar energy as a primary energy source, now they use fossil fuels as a source of energy whereby it is not renewable and needs to find new alternative to the energy sources. Klass (2003) through his research has found many industrial countries have now started an intensive research program in 1970 to develop renewable energy sources like solar energy technology. The search for a replacement of fossil fuels must be prioritized to ensure the future of human civilization.

The objective of this study is to predict the depreciation time of fossil fuel in Malaysia based on the models from previous studies. In order to predict the reserve, the world price of fossil fuels will be used and the models from previous studies will then be applied to the Malaysian data. Further, the results will be presented along with the Olduvai Theory and the Hubbert Peak Theory. This study is prioritized to the reserve and the usage of petroleum, natural gas and coal in Malaysia.

Data: The data for this study is obtained from the Energy Information Administration (EIA) and British
Petroleum (BP). EIA provides data, forecasts and analysis to promote efficient markets and public understanding regarding energy and its interaction with the economy and the environment EIA, 2010. BP, one of the largest petroleum company in the world, not only providing customers with fuel for transportation, but also published annually the statistical studies on the world's energy and provide data. These data can be obtained easily in a spreadsheet and only minor modifications are needed for analysis.

\section{MATERIALS AND METHODS}

Methodology: To predict the depreciation time of Malaysian fossil fuels, the ratio of reserves-usage model, Klass Model and Modified Klass Model, will be used for the estimation.

The ratio of fossil fuel reserve versus usage (ratio of reserve-usage): This method is used to calculate the ratio of the prediction of depreciation time of fossil fuels. With the use of fossil fuel reserves for a time, the reserve will be used based on the rate of usage and time of reserves will be diminished. This can be easily calculated from the ratio of reserves-usage. However, these methods provide only rough estimates and are not suitable for detailed analysis.

Suppose that at a certain time, a reserve of fossil fuels is R (drums) and annual usage is C (barrels per year). $\mathrm{R}$ will be reduced to a constant value of $C$ each year until it reaches zero:

$$
\begin{aligned}
& \mathrm{R}-\mathrm{C}-\mathrm{C}-\mathrm{C}-\mathrm{C}-\ldots-\mathrm{C}=0 \\
& \mathrm{R}-(\mathrm{C}+\mathrm{C}+\mathrm{C}+\mathrm{C}+\ldots+\mathrm{C})=0 \\
& \mathrm{R}-\sum_{\mathrm{i}=1}^{\mathrm{n}} \mathrm{C}=0 \\
& \mathrm{R}-\mathrm{nC}=0 \\
& \mathrm{R}=\mathrm{nC}
\end{aligned}
$$

Then, the ultimate reserves, $n$ (year) is calculated by Eq. 1 and 2:

$$
\mathrm{n}=\frac{\mathrm{R}}{\mathrm{C}}
$$

Klass model: This model was proposed by Donald L. (Klass, 1998). Klass assumes that the annual growth rate of fossil fuel usage, $\mathrm{g}\left(\% \times 10^{-2}\right)$ is a constant. Starting from the basis of annual usage, $C$, reducing the amount of reserves, $\mathrm{R}$ follows the rate of compound. The derivation of the formula allows us to calculate the depreciation time, $\mathrm{n}$ years for fossil fuels. The value of $\mathrm{g}$ is obtained from the forecast until the year 2030 in the publication of International Energy Outlook EIA, 2009: 


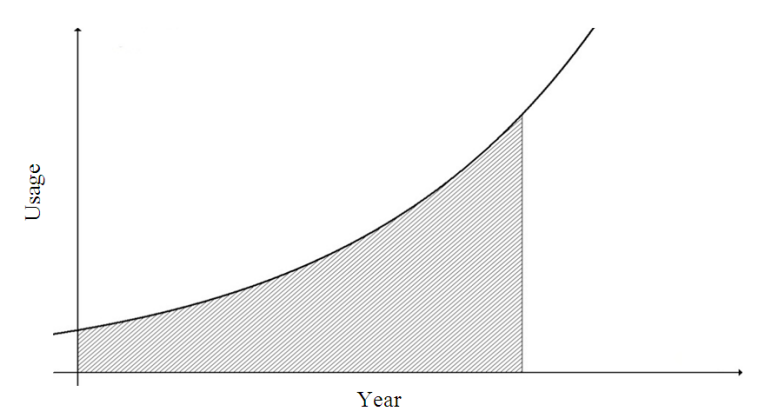

Fig. 1: The increase in the rate of consumption of fossil fuels by Klass Model

$$
\begin{aligned}
& \text { Year 1: } C_{1}=C+g C \\
& \text { Year 2: } C_{2}=C_{1}(1+g)=C(1+g)^{2} \\
& \text { Year 3: } C_{3}=C(1+g)^{3} \\
& \text { Year } n: C_{n}=C(1+g)^{n}
\end{aligned}
$$

The rate of fossil fuel consumption will increase up to the point where reserves have been exhausted.

The reserve at the start is equal to the area under the curve, which is the amount of fossil fuels usage up to $\mathrm{n}$ years, as shown in Fig. 1. Therefore, the depreciation time is estimated by the formula Eq. 3:

$\mathrm{n}=\frac{\ln (1+\mathrm{gS})}{\ln (1+\mathrm{g})}-1=\frac{\ln \left(1+\mathrm{g} \frac{\mathrm{C}+\sum \mathrm{C}_{\mathrm{i}}}{\mathrm{C}}\right)}{\ln (1+\mathrm{g})}-1$

On depreciation of $100 \%$, total consumption is equal to the reserve at a certain time, i.e. $\mathrm{R}=\mathrm{C}+\sum \mathrm{C}_{\mathrm{i}}$ therefore Eq. 4 and 5:

$$
\mathrm{n}=\frac{\ln \left(1+\mathrm{g} \frac{\mathrm{R}}{\mathrm{C}}\right)}{\ln (1+\mathrm{g})}-1
$$

Modified Klass model: Modified Klass Model is modified from the Klass Model proposed by (Shafiee and Topal, 2009). It is not the same as Klass Model which used discrete compound rate, this model uses rate of compound which is exponentially continuous. The value of $g$ is the annual growth rate of fossil fuel consumption. The basis of annual usage is also $C$. Therefore, for the year-n

$$
\mathrm{C}_{\mathrm{n}}=\mathrm{Ce}^{(\mathrm{n}-1) \mathrm{g}}
$$

The rate of fossil fuel consumption will increase up to the point where reserves have been exhausted. A reserve at the start is equal to area under the curve, which is the amount of fossil fuels up to $\mathrm{n}$ years, as shown in Fig. 1. Because reserves are equal to the amount of usage up until year-n, therefore:

$$
\begin{aligned}
& \mathrm{R}= \sum_{\mathrm{i}=1}^{\mathrm{n}} \mathrm{C}_{\mathrm{i}}=\mathrm{C}_{1}+\mathrm{C}_{2}+\ldots+\mathrm{C}_{\mathrm{n}} \\
& \mathrm{R}=\mathrm{C}+\mathrm{Ce}^{\mathrm{g}}+\mathrm{Ce}^{2 \mathrm{~g}}+\ldots+\mathrm{Ce}^{(\mathrm{n}-1) \mathrm{g}} \\
& \frac{\mathrm{R}}{\mathrm{C}}= 1+\mathrm{e}^{\mathrm{g}}+\mathrm{e}^{2 \mathrm{~g}}+\ldots+\mathrm{e}^{(\mathrm{n}-1) \mathrm{g}} \\
& \frac{\mathrm{R}}{\mathrm{C}} \mathrm{e}^{\mathrm{g}}=\mathrm{e}^{\mathrm{g}}+\mathrm{e}^{2 \mathrm{~g}}+\ldots+\mathrm{e}^{\mathrm{ng}} \\
& \frac{\mathrm{R}}{\mathrm{C}}\left(\mathrm{e}^{\mathrm{g}}-1\right)+1=\mathrm{e}^{\mathrm{ng}} \\
& \ln \left[\frac{\mathrm{R}}{\mathrm{C}}\left(\mathrm{e}^{\mathrm{g}}-1\right)+1\right]=\ln \mathrm{e}^{\mathrm{ng}}
\end{aligned}
$$

Thus, the depreciation time, $n$ year of fossil fuel is Eq. 6:

$\mathrm{n}=\frac{\ln \left[\frac{\mathrm{R}}{\mathrm{C}}\left(\mathrm{e}^{\mathrm{g}}-1\right)+1\right]}{\mathrm{g}}$

The olduvai theory: This theory states that life expectancy for the Industrial Civilization is less than or equal to 100 years, between the years 1930 to 2030 (Duncan, 2001). Since the discovery of fossil energy, human civilization is capable of entering into the Industrial Civilization. Energy production per capita increased to reach its peak in 1979 and then declined after that.

In 2030, energy production per capita will fall back to the same as in 1930 in which only meet the life expectancy of 100 years. Fig. 2 shows the Olduvai Theory for year 1930 to 2030 .

The decline began after the peak production in 1979 and was followed by three sections, Olduvai escarpment (1979-1999), Olduvai slope (2000-2011) and the Olduvai cliff (2012-2030). Olduvai escarpment indicates a decrease in the energy per capita at rate $0.33 \%$ per year. Moreover, Olduvai slope marked the peak of world production, particularly petroleum products caused by the war in the Middle East: Jerusalem Jihad. Olduvai cliff will be indicated by the termination of electricity that will be spread throughout the world for energy reduction.

The Hubbert peak theory: This theory states that the rate of production of fossil fuels seems to follow a bellshaped curve. The area under the curve will reflect an estimate of the total amount of fossil fuels we have on the planet, as shown in Fig. 3. 


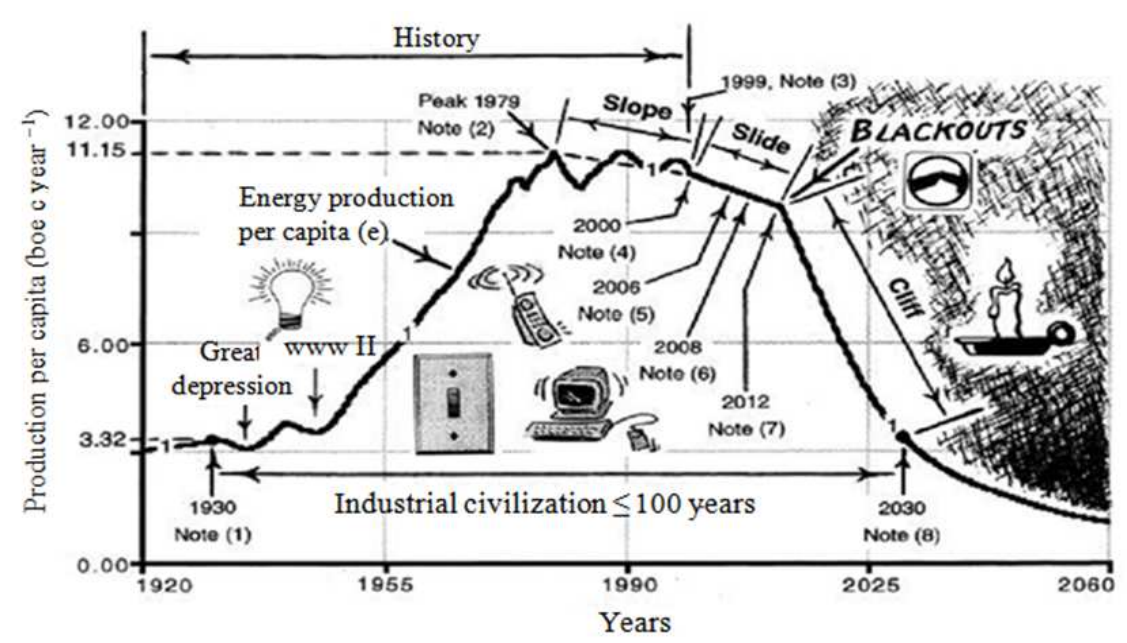

Fig. 2: Olduvai Theory: 1930-2030

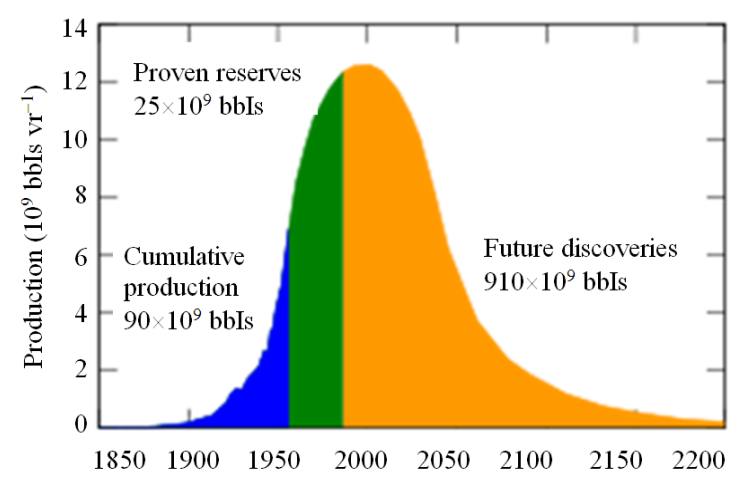

Fig. 3: The Hubbert curve by Hubbert (1956)

At the beginning of the curve, the increment in the production rate occurs because of the great effort in the rate of discovery of fossil fuels. Further, depletion of resources will lead to decreased in the production rate.

In 1956, Hubbert proposed that fossil fuel production in a given region over time would follow a roughly bell-shaped curve without giving a precise formula. He later used the Hubbert curve, the derivative of the logistic curve, for estimating future production using past observed discoveries. Hubbert assumed that after fossil fuel reserves (oil reserves, coal reserves and natural gas reserves) are discovered, production at first increases approximately exponentially, as more extraction commences and more efficient facilities are installed. At some point, a peak output is reached and production begins declining until it approximates an exponential decline.

The Hubbert curve satisfies these constraints. Furthermore, it is roughly symmetrical, with the peak of production reached when about half of the fossil fuel that will ultimately be produced has been produced. It also has a single peak. Given past oil discovery and production data, a Hubbert curve that attempts to approximate past discovery data may be constructed and used to provide estimates for future production. In particular, the date of peak oil production or the total amount of oil ultimately produced can be estimated that way.

\section{RESULTS AND DISCUSSION}

To predict the depreciation time of Malaysian fossil fuels, this study used the data of fossil fuel reserves and usage in 2006. This year was chosen because the annual growth rate of fossil fuel usage, $g$ was contained in the International Energy Outlook 2009 EIA, 2009 and will be used to estimate the value of $g$ for the years 2006 to 2030. Table 1 and 2 show data for the reserves and the usage of Malaysian fossil fuels per year.

Petroleum data and natural gas reserves can be obtained easily, but not for coal. This is because of no single organization provides the technical data and reserves for coal. However, some data can still be sought from the world's annual publication in international energy outlook. Unfortunately, data for Malaysia are not available.

Results from the ratio of fossil fuel reserve versus usage: Table 3 shows the diminution of fossil fuels in Malaysia based on the ratio of reserve-usage starting from 2006. In Malaysia, the petroleum reserves can only last for 15 years (until 2021). The natural gas still has reserves over 80 years (until 2086) and 113 years (until 2119) for coal. 


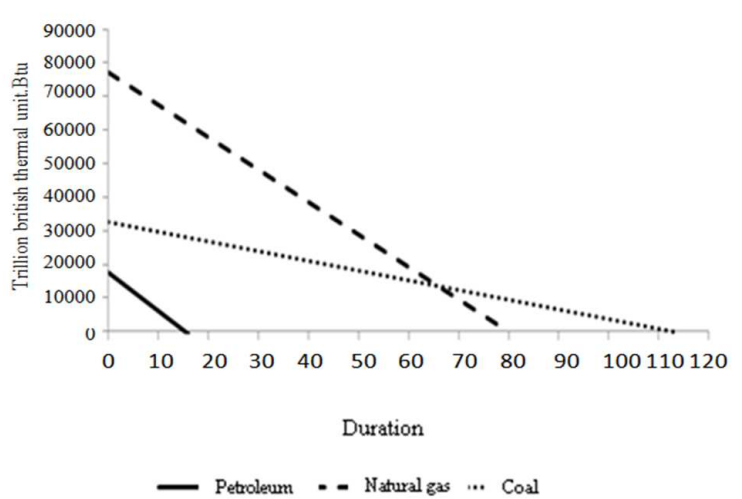

Fig. 4: Depreciation time of Malaysia fossil fuels with the ratio method

Table 1: Reserves and malaysia fossil fuels usage

\begin{tabular}{lll}
\hline Fossil fuel & Reserve & Usage (per year) \\
\hline Petroleum & 3 (thousand & 0.195061007 \\
& million barrels) & (thousand million barrels) \\
Natural gas & $\begin{array}{l}75 \text { (trillion } \\
\text { cubic feet) }\end{array}$ & $\begin{array}{l}0.9400853 \\
\text { (trillion cubic feet) }\end{array}$ \\
& $\begin{array}{l}1483.06 \text { (million } \\
\text { Coal }\end{array}$ & $\begin{array}{l}13147 \\
\text { (million tonnes) }\end{array}$ \\
\hline Source: EIA & and KTAK (Ministry & of energy, water and
\end{tabular}
communications)

Table 2: Reserves and world fossil fuel usage

\begin{tabular}{lll}
\hline Fossil fuel & Reserve & Usage (per year) \\
\hline Petroleum & 1292.93553 (thousand & 31.09860878 (thousand \\
& million barrels) & million barrels) \\
Natural gas & 6124.016 (trillion & 104.06312822 \\
& cubic feet) & (trillion cubic feet) \\
Coal & 929.3 (thousand & 6.72469310299 \\
& million tonnes) & (thousand million tonnes) \\
\hline
\end{tabular}

Source: EIA and International Energy Outlook

Table 3: The Malaysia fossil fuel depreciation with the method of ratio of fossil fuel reserve versus usage

\begin{tabular}{ll}
\hline Fossil fuel & Depreciation time (years) \\
\hline Petroleum & 15 \\
Natural gas & 80 \\
Coal & 113 \\
\hline
\end{tabular}

Fig. 4 shows a graph of the depreciation time of Malaysia fossil fuels with the ratio method. The reserve unit of any fossil fuels is standardized to the British thermal units (Btu) so that the three curves can be put into the same graph for comparisons.

This method is only used as a rough estimate, as the rate of usage is considered as a constant since 2006 and is not suitable for further analysis.

Results from the Klass model: Table 4 shows the diminution of fossil fuels in Malaysia compared to world data on Klass model starting from 2006. The value of $g$ used for petroleum, natural gas and coal are $0.01,0016$ and 0.0168 respectively.

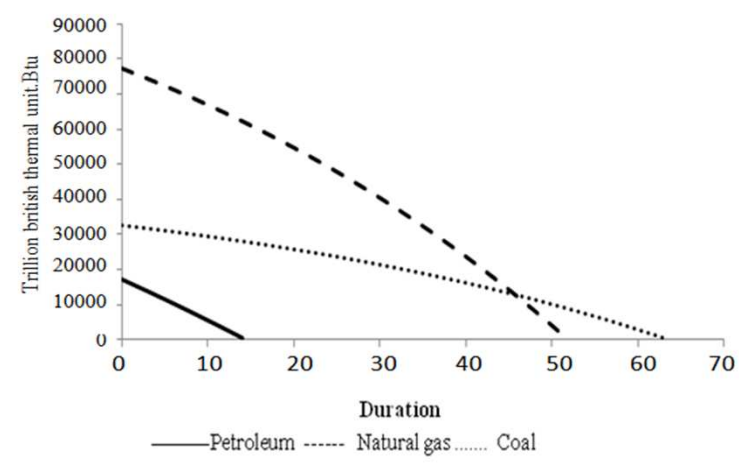

Fig. 5: The depreciation time of Malaysia fossil fuels with Klass model

Table 4: The depreciation of malaysia fossil fuels and the world fossil fuel with Klass model

\begin{tabular}{lll}
\hline Fossil fuel & $\begin{array}{l}\text { Depreciation time (years) } \\
\text { Malaysia }\end{array}$ & World \\
\hline Petroleum & 13 & 34 \\
Natural gas & 51 & 41 \\
Coal & 63 & 71 \\
\hline
\end{tabular}

Table 5: The depreciation of malaysia fossil fuels and the world fossil fuels with modified Klass model

\begin{tabular}{lll}
\hline & $\begin{array}{l}\text { Depreciation time (years) } \\
\text { Fossil fuel }\end{array}$ & World \\
\hline Petroleum & 14 & 35 \\
Natural gas & 52 & 42 \\
Coal & 64 & 72 \\
\hline
\end{tabular}

In Malaysia, it is estimated that the petroleum reserves can still be used for 13 years (until 2019) compared to the world that still can hold up to 34 years (until 2040). Natural gas and coal will still be able to survive for a period of 51 years (until 2057) and 63 years (until 2069) respectively compared to the world that only lasted until 41 years (until 2047) and 71 years (until 2077). It should be noted that natural gas reserves in Malaysia is 10 years longer than the world's natural gas. Figure 5 shows the depreciation time of Malaysia fossil fuels with Klass Model. For this result, the unit of fossil fuel reserves is also standardized to the British thermal unit, Btu.

Results from modified Klass model: Table 5 shows the diminution of fossil fuels in Malaysia compared to world data based on the Modified Klass Model starting in 2006. The $g$ value of petroleum, natural gas and coal is $0.01,0016$ and 0.0168 respectively.

In Malaysia, it is predicted that the oil can still be used for 14 years (until 2020) compared to the world that will last for 35 years (until 2041). Natural gas and coal will still be able to survive for a period of 52 years (until 2058) and 64 years (until 2070) compared to the world that can only survive up to 42 years (until 2048) and 72 years (until 2078). In addition, Fig. 6 gives the 
depreciation time of Malaysia fossil fuels with the Modified Klass Model. Like the Klass Model, British thermal unit Btu, is also used as the unit of comparisons.

The results do not differ much from the Klass model because there is only one year difference. However, the assumptions made in the Modified Model Klass gives a more accurate estimate because the assumption of the usage of fossil fuels in each year is not constant. Since Modified Klass Model has a more accurate description, explanation would be based on this model. Two assumptions have been made for this comparison. The first is the results for Malaysia and the world is independent of each other. The second assumption to get useful and accurate prediction is that, Malaysia using their own petroleum.

From the values displayed, Malaysia petroleum reserves will be exhausted in 14 years while the world petroleum can still stay up to 35 years. This means that Malaysia will spend the petroleum reserves faster than the world. Malaysia still continues to use its own natural gas for over 52 years before reserves are exhausted. The world natural gas can only survive for over 42 years and this shows that it spent more quickly when compared with Malaysia's natural gas. Among all the fossil fuels, the prediction of depreciation time of coal for Malaysia and world is a bit little longer. Coal will be exhausted in about 64 years while the world's coal will be exhausted within 72 years.

With the present rate of usage, Malaysia will spend more petroleum than natural gas and coal. In the future, natural gas and coal need to replace the petroleum and Malaysia may have to rely on other countries for petroleum. Petroleum depreciation time can still be extended if the rate of usage can be reduced by awareness of consumers on the ultimate resources of fossil fuels. However, petroleum is likely to run out at some point. In order to continue the development of human civilization, one must find alternative materials to replace fossil fuels.

The Hubbert peak theory and olduvai theory: Based on a publication from the U.S. Department of Energy (U.S. Department of Energy 2004), Fig. 7 shows that the production of petroleum for some of the non-OPEC countries have achieved the maximum level. We can see that Malaysia has reached peak in oil production in 1997 and has declined since then. The graph of oil production supported the Hubbert Peak Theory where the curvature follows the bell-shaped curve.

Figure 8-10 shows a graph of the production of Malaysian fossil fuels. Petroleum has reached peak production in 1997 and again in 2004 and start declining thereafter. From there, the forecasting of production in the future may follow the form of a bellshaped curve. The natural gas production has not shown a significant peak as the production is still increasing.

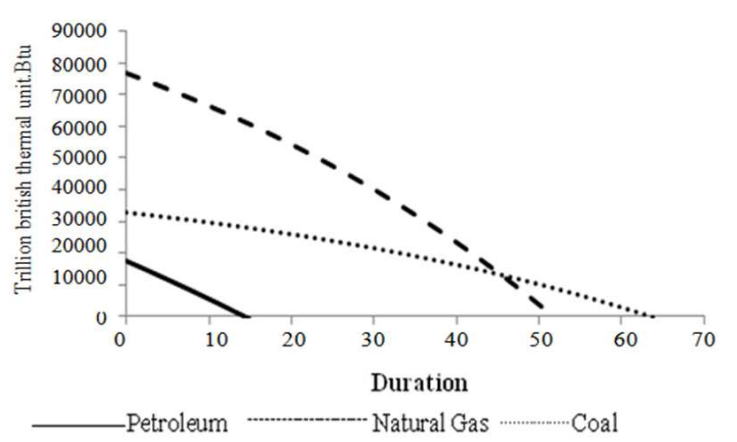

Fig. 6: The depreciation time of Malaysia fossil fuels with the modified Klass model

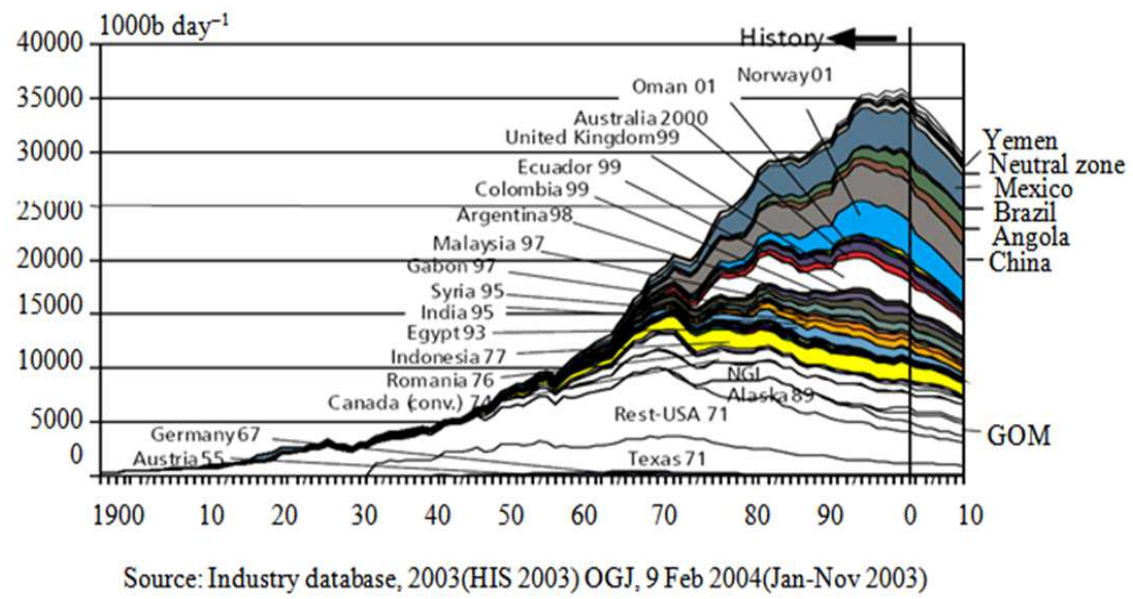

Fig. 7: 2004 U.S. government predictions for oil production in non-OPEC countries to achieve 


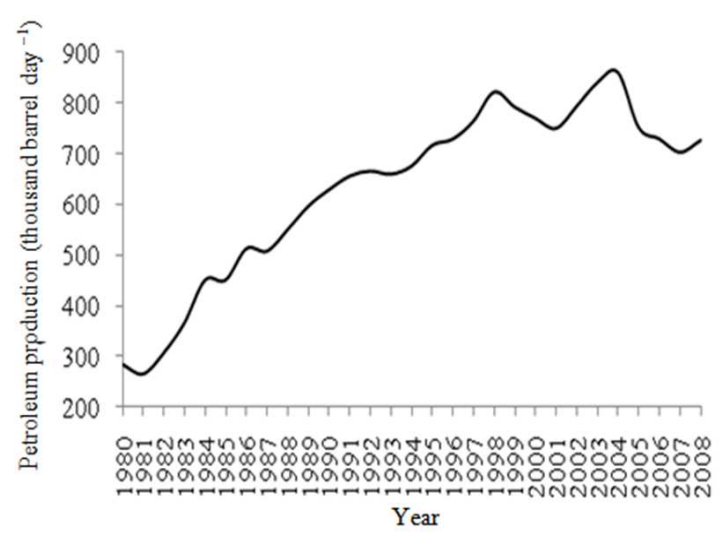

Fig. 8: Production of petroleum in Malaysia 1980-2008

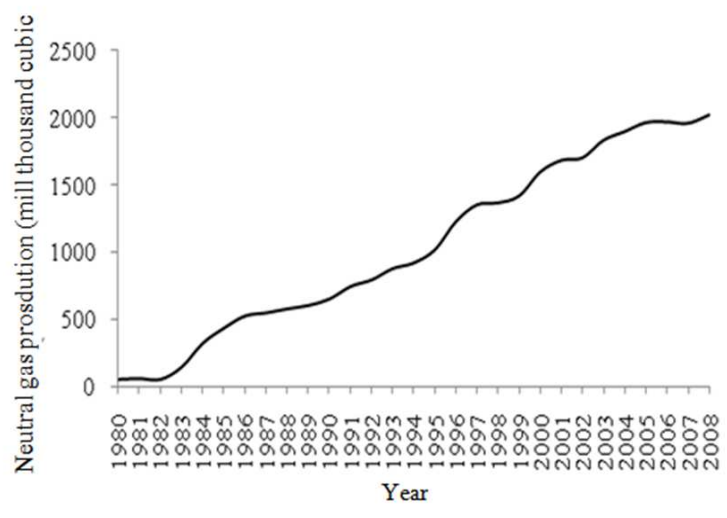

Fig. 9: The Output of natural gas in Malaysia 1980-2008

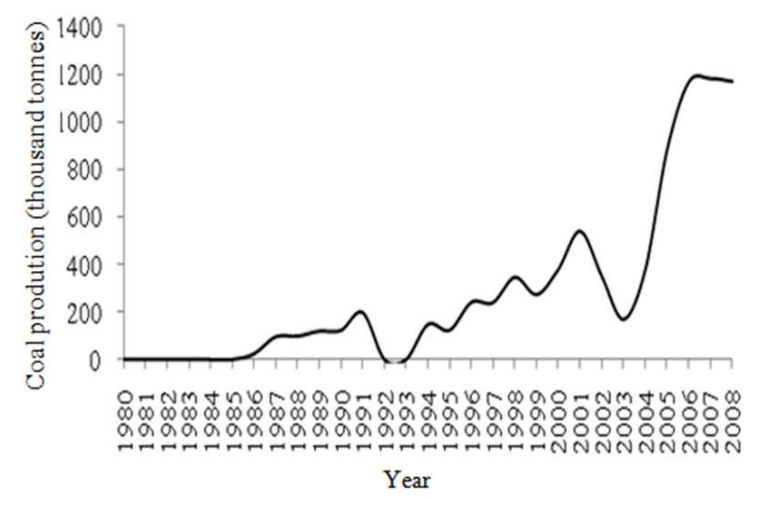

Fig. 10: Production of coal in Malaysia 1980-2008

This suggests that Malaysia can still increase their natural gas production in the near future.

The production of coal in Malaysia only started around 1985. The production increased gradually in the early days with some small decrease and then suddenly increased sharply after 2003. This graph does not show the peak of production to date and the production of coal is still increase.

\section{CONCLUSION}

From the analysis carried out, the diminution of fossil fuel based on the three models proposed can be concluded as in Table 6. Petroleum will be spent more quickly than the natural gas and coal. This is because the usage of petroleum is too broad and high in usage. Coal will still be used for a longer time and is not comparable with petroleum. After 14 years, natural gas and coal will need to replace petroleum as fossil fuels and coal would then be the major fossil fuels.

The rate of petroleum production that follows the curve of bell-shaped has explains the Hubbert Peak Theory. In about the year 2004 (Fig. 7), the rate of production of petroleum has reached a maximum and started declining since that time. This may support the results of which petroleum will be spent first. Natural gas (Fig. 8) still showed a significant of peak production and suggests that the rate of production of natural gas will still be increasing in the future. The production of coal only started around 1985 . Since that year, the rate of production (Fig. 9) increased gradually at first and rapidly after the year 2003. So far, the rate of production of coal has not yet reached the maximum level and still increasing for a very long period. Therefore, the depreciation time of coal is the longest among the three fossil fuels.

The life expectancy of Industrial Civilization which is explained by the Olduvai Theory is approximately 100 years, between 1930 and 2030 . Based on the results of this study and the results in Table 6, we need to worry about the fall of the Industrial Civilization that is caused by the depreciation of fossil fuels. This is because the expectation of the end of Industrial Civilization, which falls in 2030, is within the period of depreciation of the three fossil fuels. Petroleum will be spent in the year 2020, followed by natural gas in 2058 and coal around the year 2066. So far, our country is not facing disconnection of electricity as in other developed countries.

Table 6: The Malaysia fossil fuel depreciation with three models

\begin{tabular}{llll}
\hline & Depreciation time (years) & \\
& Ratio of reserve- & & Modified Klass \\
Fossil fuel & usage & Klass model & model \\
\hline Petroleum & 15 & 13 & 14 \\
Natural gas & 80 & 51 & 52 \\
Coal & 113 & 63 & 64 \\
\hline
\end{tabular}


When this happens, it gives the meaning that we are approaching the end of the Industrial Civilization. If there is no substance that can replace fossil fuels were found to continue the Industrial Civilization, human civilization will be facing the fate of collapse.

There is no doubt that fossil fuels have helped in the development of human civilization. However, it has also caused environmental damage in some sense. Burning fossil fuels will produce carbon dioxide and contributed to global warming. A synthetic material of petroleum has been polluting the environment as the materials are highly toxic. Therefore, many awareness campaigns about the importance of preserving and conserving the environment become prioritized. If everyone is aware of the energy crisis and the environmental destruction, many people will save energy and the fossil fuels can be used longer as well as conserving the environment.

\section{ACKNOWLEDGEMENT}

This study was funded by the research grant UKM-DIPM-082-2011 under the University Kebangsaan Malaysia.

\section{REFERENCES}

Duncan, R.C., 2001. World energy production, population growth and the road to the olduvai gorge. Population Environ., 22: 503-522. DOI: 10.1023/A:1010793021451

Hubbert, M.K., 1949. Energy from fossil fuels. Science, 109: 103-109.

Klass, D.L. 1998. Biomass for renewable energy, fuels and chemicals. 1st Edn., Academic Press, San Diego, ISBN-10: 0124109500, pp: 651.

Klass, D.L., 2003. A critical assessment of renewable energy usage in the USA. Energy Policy, 31: 353367. DOI: 10.1016/S0301-4215(02)00069-1

Shafiee, S. and E. Topal, 2009. When will fossil fuel reserves be diminished? Energy Policy, 37: 181189. DOI: 10.1016/j.enpol.2008.08.016 